\title{
Perceções dos docentes sobre a avaliação externa das escolas em Portugal ${ }^{1}$
}

\author{
Teachers' perceptions on the external evaluation of schools in Portugal
}

\section{Percepciones de los docentes sobre la evaluación externa de las escuelas en Portugal}

\author{
Joana Raquel Faria de Sousa ${ }^{2}$ \\ Universidade do Minho, Investigadora do Centro de Investigação em Educação (CIEd) no \\ Instituto de Educação \\ José Augusto Pacheco ${ }^{3}$ \\ Universidade do Minho, Professor Catedrático em Ciências da Educação no Instituto de \\ Educação
}

Resumo: O estudo apresentado neste artigo surge de uma investigação realizada no âmbito do Observatório de Autoavaliação de Escolas, tendo por objetivo principal compreender tendências nas perceções dos docentes sobre os efeitos da Avaliação Externa das Escolas (AEE) na realidade portuguesa. Através de um estudo quantitativo, baseado num inquérito por questionário dirigido a docentes de Agrupamentos de Escolas e Escolas não Agrupadas da rede do Ministério da Educação, na região Norte de Portugal, são analisados os resultados com base no processamento de dados estatísticos, dos quais são enfatizadas duas tendências principais: a perceção dos docentes relativamente à influência da AEE na dinamização dos órgãos intermédios de gestão, na articulação curricular, nos mecanismos de qualidade que promovem a educação, na discussão sobre a organização interna da escola, na orientação para os resultados de aprendizagem dos alunos, na Avaliação Externa de Aprendizagens, no desenvolvimento profissional dos docentes e na promoção da imagem

\footnotetext{
1 Este trabalho é financiado pelo Centro de Investigação em Educação (CIEd), projetos UID/ CED/1661/2013 e UID/CED/1661/2016, Instituto de Educação, Universidade do Minho, por intermédio de fundos nacionais da FCT/MCTES-PT.

2 Mestre em Ciências da Educação pelo Instituto de Educação da Universidade do Minho, Braga, Portugal; doutoranda em Ciências da Educação; Especialista em Desenvolvimento Curricular no Instituto de Educação da Universidade do Minho, com Bolsa de Doutoramento da Fundação para a Ciência e a Tecnologia (SFRH/BD/93389/2013); Investigadora no Centro de Investigação em Educação (CIEd) do Intituto de Educação da Universidade do Minho.

3 Professor Doutor em Ciências da Educação pelo Instituto de Educação da Universidade do Minho, Braga, Portugal; Professor Catedrático em Ciências da Educação no Instituto de Educação da Universidade do Minho; Investigador no Centro de Investigação em Educação (CIEd) do Intituto de Educação da Universidade do Minho; Presidente do Instituto de Educação da Universidade do Minho.
} 
social da escola; e a indefinição da perceção dos docentes relativamente à melhoria dos apoios pedagógicos e à contribuição para a diferenciação curricular, como efeito da AEE. Palavras-chave: Avaliação externa das escolas. Avaliação institucional. Inspeção das escolas. Currículo.

Abstract: The study presented in this article emerges from an investigation carried out within the Schools Self-evaluation Observatory, with the main purpose of understanding the trends in teachers' perceptions regarding the effects of the External Evaluation of Schools (EES) on the Portuguese reality. Through a quantitative study based on a questionnaire survey applied to teachers of the School Groups and Non-Grouped Schools of the Ministry of Education network in the Northern region of Portugal, the results are analyzed through data processing from which two main tendencies are emphasized: the teachers 'perception of the influence of the EES in the intermediate management bodies' dynamics, in the curricular articulation, in the quality mechanisms that promote education, in the discussion about the internal organization of the school, in the orientation to the students learning outcomes, in the External Evaluation of Learning, in the professional development of the teachers and in the promotion of the social image of the school; the undefined teachers' perception regarding the improvement of pedagogical support and the contribution to curricular differentiation as an effect of EES.

Keywords: External evaluation of schools. Institutional evaluation. School inspections. Curriculum.

Resumen: El estudio que aqui se presenta surge de una investigación realizada en el marco del Observatorio de Autoevaluación de Escuelas, realizada con el principal objetivo de comprender tendencias en las percepciones de los docentes sobre los efectos de la Evaluación Externa de las Escuelas (EEE) de la realidad Portuguesa. A través de un estudio cuantitativo basado en una encuesta por cuestionario dirigido a docentes de Agrupamientos de Escuelas y Escuelas no Agrupadas de la red del Ministerio de Educación, en la región Norte de Portugal, se han analizado los resultados a través del procesamiento de datos estadísticos, de los cuales se enfatizan las dos mayores tendencias: percepción de los docentes respecto a la influencia de la EEE en la dinamización de los órganos intermedios de gestión, en la articulación curricular, en los mecanismos de calidad que promueven la educación, en la discusión sobre la organización interna de la escuela, en la orientación hacia los resultados de aprendizaje de los alumnos, en la Evaluación Externa de Aprendizajes, en el desarrollo profesional de los docentes y en la promoción de la imagen social de la escuela; la 
indefinición de la percepción de los docentes respecto a la mejora de los apoyos pedagógicos ya la contribución a la diferenciación curricular, como efecto de la EEE. Palabras clave: Evaluación externa de las escuelas. Evaluación institucional. Inspección de las escuelas. Currículo.

\section{INTRODUÇÃO}

A presente análise enquadra-se num estudo realizado pelo Observatório de Autoavaliação de Escolas, de agora em diante designado Observatório, tendo como objetivo principal compreender os efeitos do processo de Avaliação Externa das Escolas (AEE), monitorizado pela Inspeção-Geral da Educação e Ciência (IGEC) em Portugal, nas dimensões organizacional, curricular e pedagógica dos Agrupamentos de Escolas ou Escolas não Agrupadas, adiante designadas como escolas. A problemática do estudo está centrada, assim, na avaliação institucional de escolas (DIAS SOBRINHO, 1995), que em Portugal tem sido consagrada pela terminologia avaliação externa das escolas.

O Observatório ${ }^{4}$ foi criado no contexto do sistema de AEE, implementado em Portugal desde o ano 2002, e no seguimento de um projeto de investigação financiado pela Fundação para a Ciência e a Tecnologia (FCT-PTDC/CPECED/111674/2010), entre 2012 e 2015, que centrou o seu objeto de estudo nos efeitos da AEE. O referencial da AEE tem sido reenquadrado do ponto de vista normativo, sendo que essas alterações têm aportado impactos nas escolas, tal como alguns estudos têm destacado (PACHECO, 2015; 2016). ${ }^{5}$ Com efeito, o presente estudo procura descrever, de forma sumária, o modelo de AEE implementado pela IGEC em Portugal e analisar as tendências do seu impacto em Agrupamentos de Escolas e Escolas não Agrupadas da rede do Ministério da Educação, na região Norte de Portugal.

A discussão deste estudo é iniciada com a descrição do sistema de AEE em Portugal e a sua operacionalização, ainda que enquadrado no contexto europeu, para posteriormente ser apresentado e analisado o estudo empírico realizado.

\footnotetext{
4 Sobre o Observatório de Autoavaliação de Escolas consultar o site do Centro de Investigação em Educação do Instituto de Educação da Universidade do Minho. Disponível em: <http://www.cied.uminho.pt/ Default.aspx?tabid=4\&pageid=316\&lang=pt-PT $>$.

5 Sobre o projeto de investigação Impacto e Efeitos da Avaliação Externa de Escolas no Ensino não Superior consultar o site. Disponível em: <http://webs.ie.uminho.pt/avaliacaoexternaescolas/>.
} 


\section{O SISTEMA DE AVALIAÇÃO EXTERNA DAS ESCOLAS EM PORTUGAL}

Contributos de projetos e programas nacionais, surgidos na década de 1990, e um contexto internacional favorável possibilitaram a implementação da AEE em Portugal (FIALHO, 2009; AFONSO, 2015) como o sistema de avaliação da educação e do ensino não superior, consagrado no Artigo $1^{\circ}$ da Lei n. 31/2002 (PORTUGAL, 2002). Treze anos mais tarde, a AEE foi considerada pela Comissão Europeia como um garante da qualidade educativa no continente Europeu, tendo sido implementada na grande maioria dos países europeus, com enfoque nas atividades realizadas na escola, sem a assunção de responsabilidades individuais pelos resultados obtidos pela escola (EUROPEAN COMISSION/EACEA/EURYDICE, 2015a). Para o nascimento do sistema de AEE, contribuíram, sobretudo, o programa de Avaliação Integrada, desenvolvido pela Inspeção-Geral da Educação (IGE) entre 1999 e 2002, bem como a metodologia proposta pela European Foundation for Quality Management (EFQM) e pelo projeto How Good is Our School da Escócia (OLIVEIRA et al., 2006).

Criado em 2002, o sistema da AEE foi implementado em Portugal, tendo sido atribuído à IGEC a sua tutela e coordenação, organismo do serviço central da administração direta do Estado dotado de autonomia administrativa (PORTUGAL, 2012), que a perspetivou como uma mais-valia para o desenvolvimento das escolas e que a definiu segundo quatro objetivos (INSPEÇÃO-GERAL DA EDUCAÇÃO E CIÊNCIA, 2011b):

i. Promover o progresso das aprendizagens e dos resultados dos alunos, identificando pontos fortes e áreas prioritárias para a melhoria do trabalho das escolas;

ii. Incrementar, a todos os níveis, a responsabilização, validando as práticas de autoavaliação das escolas;

iii. Fomentar a participação na escola da comunidade educativa e da sociedade local, oferecendo um melhor conhecimento público do trabalho das escolas;

iv. Contribuir para a regulação da educação, dotando os responsáveis pelas políticas educativas e pela administração das escolas de informação pertinente.

Ao Conselho Nacional de Educação, organismo de aconselhamento do Estado, independente do Ministério da Educação português, a quem compete a emissão de opiniões, pareceres e recomendações sobre questões em matéria de 
política educativa em Portugal (CONSELHO NACIONAL DA EDUCAÇÃO, [2015]), compete garantir a exequibilidade do sistema de AEE, como é definido pela Lei n. 31/2002 (PORTUGAL, 2002).

A AEE é implementada através de um sistema de avaliação aplicado por uma equipa de avaliadores externos constituída por dois inspetores da IGEC e um Perito Externo que analisam as escolas-alvo baseados numa metodologia qualitativa e quantitativa ao longo de três fases, com a possibilidade de existir uma quarta fase. $\mathrm{Na}$ primeira fase, a equipa de avaliadores recolhe dados para análise, através da análise documental de documentos estruturantes da escola (ex: documento de apresentação da escola, projeto educativo, regulamento interno, relatório de autoavaliação, planos de estudo, plano anual ou plurianual de atividades, bem como outros documentos pertinentes) e na análise da informação estatística, nomeadamente, o perfil de escola, questionários de satisfação, cuja população são os atores da própria comunidade educativa interna (alunos, famílias e trabalhadores docentes e não docentes) e respetiva análise dos resultados. Na segunda fase, é realizada uma visita à escola pela equipa de avaliadores que inclui a observação direta (ex: instalações e equipamentos, clima educativo) e entrevistas de painel a membros representativos da comunidade educativa interna (escola) e externa (restante comunidade). Na terceira fase, e após a recolha e análise dos dados obtidos, a equipa de avaliadores emite um parecer analítico à tutela sobre os resultados apurados, com a sua publicação no site da IGEC, enviando o parecer à escola avaliada. A existência de uma quarta fase está relacionada com a reação e posterior decisão da escola avaliada sobre o parecer da equipa de avaliação, uma vez que, em caso de discordância, a escola poderá realizar um contraditório (no prazo de 15 dias úteis), no caso de não se identificar com o conteúdo do parecer ou a avaliação final, permitindo que a escola possa contestar ou contra-argumentar. Importa ressalvar que, perante os contraditórios realizados pelas escolas e enviados à IGEC, este organismo elabora um documento em resposta, porém, embora essa situação esteja prevista, até o presente as respostas das equipas de avaliação aos contraditórios nunca se traduziram numa alteração aos juízos avaliativos ou à classificação final, mas apenas em alterações relativas a factos concretos sem relevância suficiente para alterar a classificação da escola (INSPEÇÃO-GERAL DA EDUCAÇÃO, 2011b). Assim, podemos reiterar a afirmação de que "o contraditório é considerado nos aspetos fatuais, e não propriamente no que é considerado juízo valorativo.” (PACHECO, 2016, p. 70). Para além do contraditório, a escola pode submeter um recurso à tutela, porém este 
recurso é avaliado pela própria IGEC, demonstrando a omnipresença da Inspeção no processo de AEE em Portugal (PACHECO, 2016) e suscitando diversas críticas, que o Conselho Nacional da Educação apontou como características a melhorar na AEE, nomeadamente a "forma como o contraditório está a ser organizado e à ausência de mecanismos de recurso." (CONSELHO NACIONAL DA EDUCAÇÃO, 2010, p. 31832).

O sistema de avaliação da educação e do ensino não superior em Portugal rege-se por um referencial padronizado, organizado pela IGEC num modelo cíclico, em que todas as escolas são avaliadas em intervalos regulares pela IGEC, à luz do que vem sendo realizado nos restantes países da Europa (EUROPEAN COMISSION/ EACEA/EURYDICE, 2015a). Até o momento registaram-se dois ciclos de AEE, apenas orientados para as escolas do ensino público. Um primeiro ciclo que iniciou em 2006 e terminou em 2011, e um segundo ciclo que iniciou no mesmo ano civil e terminou em 2017. Após dois ciclos de implementação, a AEE em Portugal encontrase no dealbar de um terceiro ciclo. As experiências dos ciclos anteriores revelaram variedade nos domínios avaliados, sendo que cada um destes foi composto por diferentes campos de análise e referentes, bem como níveis de classificação (Quadro 1). O terceiro ciclo encontra-se presentemente em fase de preparação, estando prevista a sua vigência entre 2018 e 2022, esperando-se que mantenha a continuidade dos domínios em avaliação do segundo ciclo, podendo ser enfatizados os aspetos da AEE que promovam um maior envolvimento das escolas em todo o processo, sobretudo as que estão ligadas à valorização da autoavaliação, para além de poder abranger os Estabelecimentos de Ensino Particular e Cooperativo, bem como, poder reforçar determinadas dimensões da escola.

Quadro 1 - Domínios e classificações nos dois primeiros ciclos da Avaliação Externa das Escolas (AEE) em Portugal

\begin{tabular}{|c|c|c|c|}
\hline \multicolumn{2}{|c|}{$1^{\circ}$ ciclo AEE (2006-2011) } & \multicolumn{2}{|c|}{$2^{\circ}$ ciclo AEE (2011-2017) } \\
\hline Domínios & Classifica & Domínios & Classificação \\
\hline $\begin{array}{ll}\text { - } & \text { Resultados; } \\
\text { - } & \text { Prestação do serviço } \\
& \text { educativo; } \\
\text { - } & \text { Liderança e capacidade } \\
\text { de autorregulação; } \\
\text { - } & \text { Melhoria. }\end{array}$ & $\begin{array}{ll}\text { - } & \text { Muito bom. } \\
\text { - } & \text { Bom. } \\
\text { - } & \text { Suficiente. } \\
\text { Insuficiente. }\end{array}$ & $\begin{array}{ll}\text { - } & \text { Prestação do ser- } \\
& \text { viço educativo; } \\
\text { - } & \text { Resultados; } \\
\text { - } & \text { Liderança e } \\
& \text { gestão. }\end{array}$ & $\begin{array}{ll}\text { - } & \text { Excelente. } \\
\text { - } & \text { Muito bom. } \\
\text { - } & \text { Bom. } \\
\text { - } & \text { Insuficiente. } \\
\end{array}$ \\
\hline
\end{tabular}

Fonte: Inspeção-Geral da Educação (2010, 2011a) e Inspeção-Geral da Educação e Ciência (2016a, 2016b). 
De seguida, é apresentado o quadro de referência atual da AEE (Quadro 2), do qual destacamos o domínio da prestação do serviço educativo, uma vez que é sobretudo sobre este domínio que recai o estudo aqui apresentado.

Quadro 2 - Quadro de referência do segundo ciclo da Avaliação Externa das Escolas (AEE) em Portugal

\begin{tabular}{|l|l|}
\hline \multicolumn{1}{|c|}{ Domínios } & \multicolumn{1}{c|}{ Campos de análise } \\
\hline \multirow{4}{*}{ Resultados } & Resultados académicos \\
\cline { 2 - 2 } & Resultados sociais \\
\cline { 2 - 2 } & Reconhecimento da comunidade \\
\hline \multirow{4}{*}{ Prestação do serviço educativo } & Planeamento e articulação \\
\cline { 2 - 2 } & Práticas de ensino \\
\cline { 2 - 2 } & Monitorização e avaliação do ensino e das aprendizagens \\
\hline \multirow{3}{*}{ Liderança e gestão } & Liderança \\
\cline { 2 - 2 } & Gestão \\
\cline { 2 - 2 } & Autoavaliação e melhoria \\
\hline
\end{tabular}

Fonte: Inspeção-Geral da Educação e Ciência, (2016a).

Tendo em conta o contexto Europeu, verifica-se que o sistema de AEE em Portugal segue uma metodologia de implementação alinhada com a maioria dos sistemas educativos homólogos europeus (EUROPEAN COMISSION/EACEA/ EURYDICE, 2015a).

\section{METODOLOGIA DE INVESTIGAÇÃO}

A investigação realizada teve como objetivo compreender tendências nas perceções dos docentes sobre os efeitos da AEE, em Portugal, de modo a compreender a relação entre o sistema de AEE e o processo de desenvolvimento do campo do currículo.

Perante este objetivo foi elaborado um inquérito por questionário online, aplicado a uma amostra intencional de docentes dos Agrupamentos de Escolas e Escolas não Agrupadas da rede do Ministério da Educação, na região Norte de Portugal, que integram o Observatório, que tem um papel consultivo especializado no âmbito da AEE, atendendo ao protocolo de colaboração entre escolas e a Universidade do Minho. O questionário utilizado tem quatro secções: 1) Caracterização dos 
participantes; 2) Caraterísticas do modelo de AEE da IGEC; 3) Caraterísticas do processo de AEE da IGEC e Autoavaliação das Escolas; 4) Efeitos organizacionais, curriculares e pedagógicos do atual modelo de AEE da IGEC. Para efeitos da presente análise, são considerados os dados recolhidos nas secções 1 e 4 . A primeira secção é constituída por questões de múltipla escolha relativas à informação demográfica e de caracterização da situação profissional do docente. A quarta secção engloba um total de 10 questões, entre as quais duas estavam orientadas a compreender a perceção do docente relativamente às afirmações enunciadas, pedindo-se para selecionar a opção desejada em questões de escolha múltipla. As restantes afirmações seguiram uma escala do tipo Likert de quatro itens, sendo que 1 significa discordo totalmente e 4 expressa concordo totalmente, existindo também a opção sem opinião.

$\mathrm{O}$ período de recolha de questionários decorreu entre junho e julho de 2016, tendo sido validados 276 inquéritos, através de uma amostragem aleatória determinada pela participação das escolas no referido Observatório.

\section{RESULTADOS DE INVESTIGAÇÃO}

De seguida, são apresentados os resultados do estudo empírico, nomeadamente a caracterização dos participantes, bem como a descrição e a análise dos resultados obtidos no inquérito por questionário.

\subsection{CARACTERIZAÇÃO DOS PARTICIPANTES}

No estudo participaram 276 sujeitos, todos docentes de Agrupamentos de Escolas ou Escolas não Agrupadas da rede do Ministério da Educação em Portugal, da região Norte de Portugal.

A caracterização dos respondentes inquiridos fez-se mediante a idade, o género, as habilitações académicas, o tempo de serviço na escola atual, o tempo de serviço docente (total de anos de docência), a dimensão da escola e o ano letivo em que foi realizada a última AEE na respetiva escola.

Relativamente ao género, $75 \%$ dos inquiridos são do sexo feminino, e $25 \%$ do sexo masculino. Dos 276 participantes, verifica-se uma maior prevalência de docentes com idades compreendidas entre os 41 e os 50 anos (43\%), seguida da faixa de idades entre os 51 e os 60 anos (37\%). O intervalo de idades entre os 20 e 
os 30 anos corresponde a $1 \%$ dos participantes, o de 31 a 40 anos incluiu $15 \%$ dos docentes participantes e o de 61 anos ou mais corresponde a $4 \%$ dos respondentes. No que concerne às habilitações académicas dos inquiridos, a grande maioria tem uma licenciatura (71\%), sendo a segunda opção mais prevalente o mestrado, com $20 \%$ dos resultados. A pós-graduação foi a terceira opção mais escolhida, representando $20 \%$ dos participantes, seguindo-se o bacharelato (2\%). A distribuição dos participantes pelos níveis de ensino em que lecionam ${ }^{6}$ revelou o predomínio dos docentes do $3 .^{\circ}$ ciclo do ensino básico e ensino secundário (46\%), seguindo-se os docentes do $1 .^{\circ}$ ciclo do ensino básico (22\%) e os docentes do $2 .^{\circ}$ ciclo do ensino básico $(20 \%)$. Com menor prevalência registaram-se os docentes de educação pré-escolar ( $9 \%$ ) e os docentes de educação especial (3\%). A variação do tempo de serviço docente de cada um dos participantes foi também alvo de estudo, com a maioria dos participantes a apresentarem entre 19 e 24 anos (32\%), seguidos pelos grupo de docentes com tempo de serviço entre os 25 e os 30 anos (24\%), com mais de 30 anos (21\%), entre os 13 e os 18 anos (18\%) e entre os 7 e os 12 anos (4\%). O menos prevalente foi o intervalo de tempo de serviço entre zero e seis anos (1\%). Procurou-se, também, perceber o tempo de serviço do docente na escola atual, sendo que neste indicador o tempo de docência na mesma escola foi predominantemente o intervalo mais reduzido, com a maioria dos inquiridos a selecionar entre zero e seis anos (31\%), sendo imediatamente seguido pelo intervalo subsequente, entre sete e 12 anos (30\%). O intervalo com menos respostas recolhidas corresponde ao período de mais de 30 anos de serviço na escola atual (3\%). Entre 13 a 18 anos de serviço responderam 18\% dos docentes, entre 19 e 24 anos de serviço $13 \%$ dos docentes e apenas 5\% dos respondentes se situam entre os 25 e os 30 anos. Sobre a dimensão da escola, procurou-se perceber qual o número de alunos da escola em que cada um dos respondentes se insere. Verificou-se uma maior incidência de inquiridos a afetos a escolas entre 501 e 1000 alunos (35\%), seguindo-se o intervalo de escolas com 500 ou menos alunos $(25 \%)$ e as escolas com 1.001 a 1.500 alunos (24\%). As escolas com menos prevalência foram as com mais de 2000 alunos (5\%). A última questão, relativa à caracterização dos respondentes, diz respeito à determinação do ano letivo em que se sucedeu a última AEE na escola de cada inquirido. Na maioria das situações, o ano letivo 2015/2016 foi o período mais

$\overline{6}$ Sobre o Sistema de Educação e Formação em Portugal, ver também Ministério da Educação (2007). 
prevalente (41\%), seguindo-se o ano letivo 2013/2014 (28\%), o ano letivo 2012/2013 (17\%) e, por último, o ano letivo 2011/2012 (14\%).

A análise dos dados permitiu constatar que, em termos gerais, a maioria dos inquiridos corresponde à realidade portuguesa, uma vez que são predominantemente do sexo feminino, têm idades compreendidas entre 41 e 50 anos e têm o grau de licenciado (EUROPEAN COMMISSION/EACEA/EURYDICE, 2015b). Os respondentes são, na sua maioria, docentes do $3 .^{\circ}$ ciclo do ensino básico e ensino secundário, executando funções como docentes entre 19 e 24 anos, dos quais estão a trabalhar na mesma escola entre zero e 12 anos. Na maioria dos casos são docentes em escolas com um número total de alunos entre os 501 e 1000.

\subsection{DESCRIÇÃO E ANÁLISE DOS RESULTADOS}

A recolha de dados relativos à perceção dos inquiridos sobre os efeitos organizacionais, curriculares e pedagógicos do atual modelo de AEE da IGEC efetuouse através de um inquérito por questionário, com 10 questões, cujos resultados obtidos são aqui apresentados e analisados.

Quando questionados sobre a influência positiva da AEE (Gráfico 1), a maioria dos docentes sublinha o efeito positivo da AEE na dinamização dos órgãos intermédios de gestão (ligados à coordenação e supervisão pedagógica). Em segundo lugar, os participantes identificam a influência no trabalho colaborativo docente nos departamentos curriculares (29\%). Em terceiro lugar, com 16\%, destacam o efeito positivo da AEE na promoção da supervisão pedagógica dos docentes. Por fim, 14\% dos respondentes identificam o efeito positivo da AEE no trabalho pedagógico com a(s) sua(s) turma(s). 
Gráfico 1 - A AEE (Avaliação Externa das Escolas) da IGEC tem uma influência positiva...

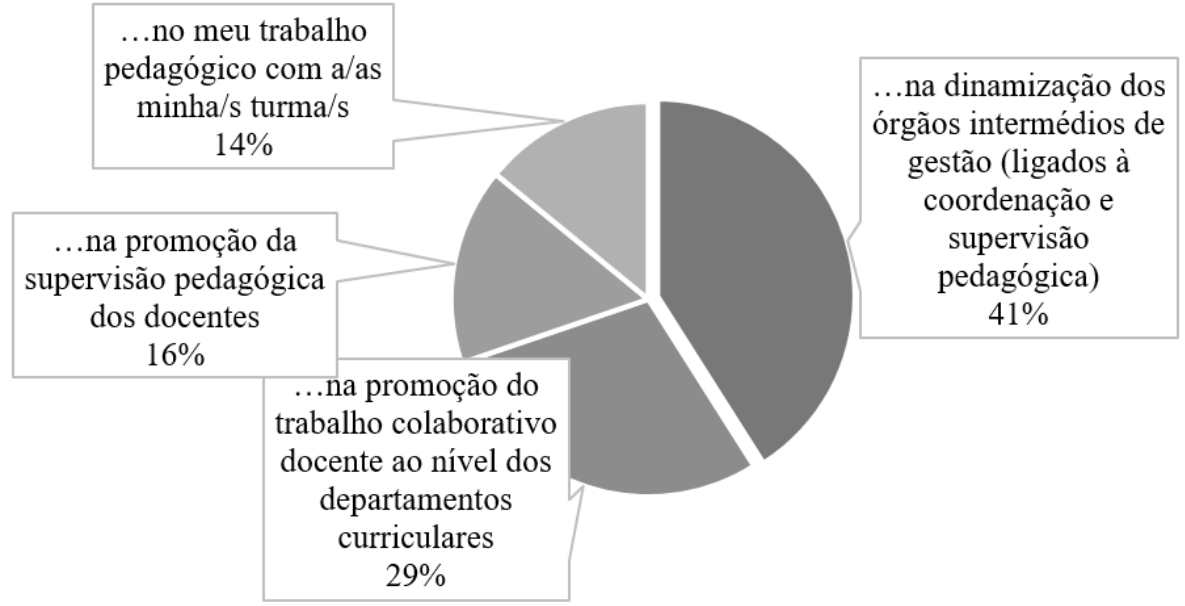

Fonte: os autores.

De um conjunto de três opções possíveis, relativas ao tipo de fenómenos promovidos pela AEE (Gráfico 2), a mais prevalente, com 38\%, é a articulação curricular. O segundo fenómeno mais promovido pela AEE na perceção dos inquiridos é a colaboração pedagógica, com 33\%. A terceira opção, com $29 \%$, é a articulação curricular do mesmo ciclo e/ou nível de ensino.

Gráfico 2 - A AEE (Avaliação Externa das Escolas) da IGEC promove a...

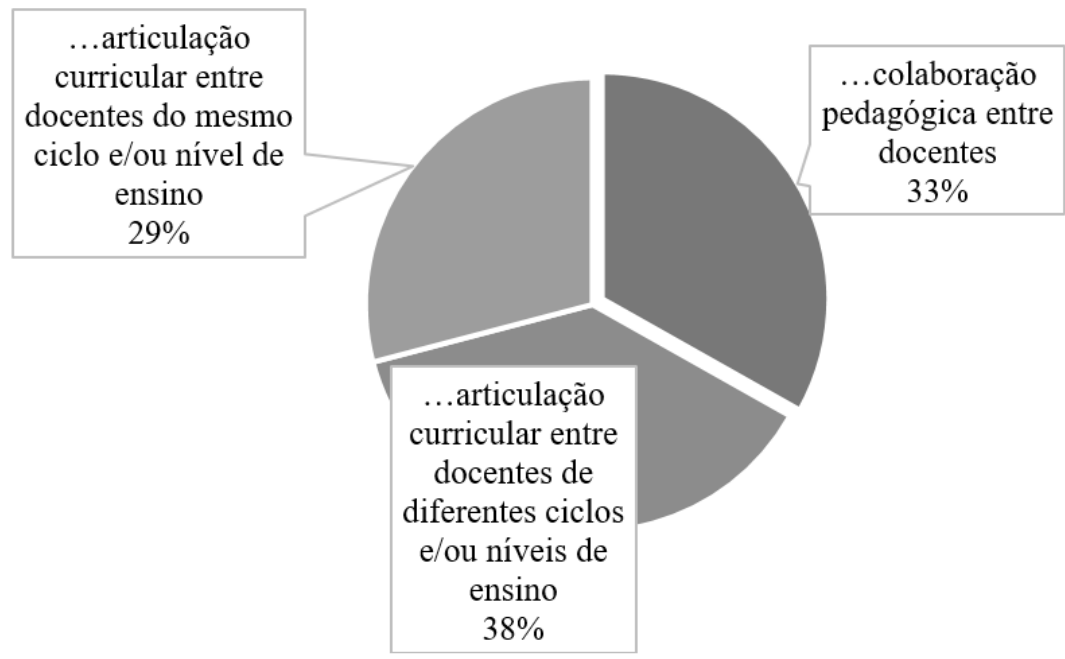

Fonte: os autores. 
No que concerne à concordância com o facto de a AEE contribuir para que a escola desenvolva mecanismos de qualidade que promovem a educação (Gráfico 3), os respondentes referem maioritariamente concordar (58\%,), enquanto $13 \%$ discordam, $5 \%$ concordam totalmente e $2 \%$ dos inquiridos discordam totalmente com a afirmação. Do total dos participantes, $21 \%$ referem não ter opinião no que diz respeito à afirmação.

Gráfico 3 - A AEE (Avaliação Externa das Escolas) contribui para que a escola desenvolva mecanismos de qualidade que promovem a educação

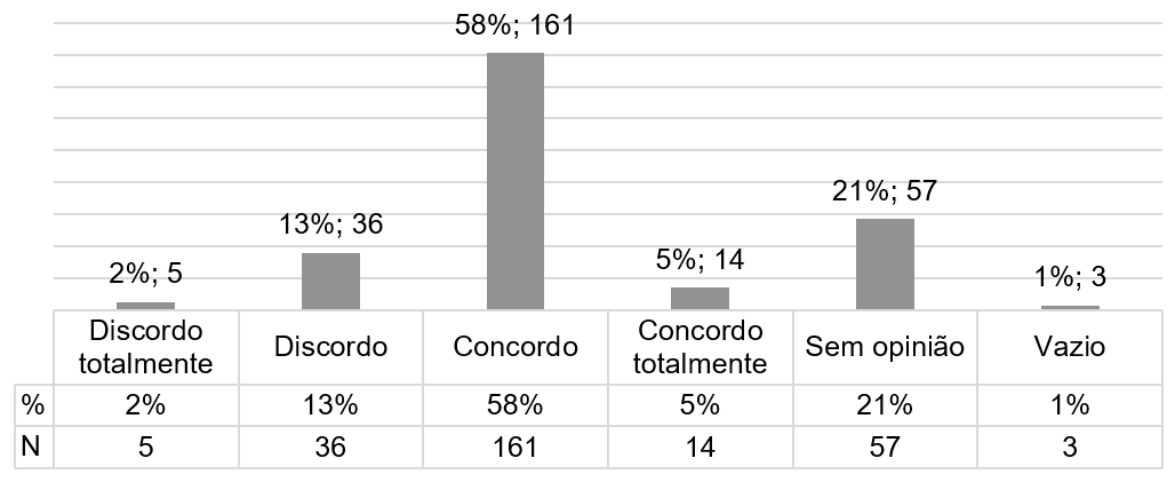

Fonte: os autores.

No gráfico 4 observa-se que $41 \%$ dos respondentes referem concordar com o contributo da AEE para o desenvolvimento profissional dos docentes. Por outro lado, $21 \%$ discordam. Em igualdade percentual, com 3\% regista-se a discordância total e a concordância total. Sem opinião regista-se a resposta de $29 \%$ dos respondentes.

Gráfico 4 - A AEE (Avaliação Externa das Escolas) contribui para o desenvolvimento profissional dos docentes

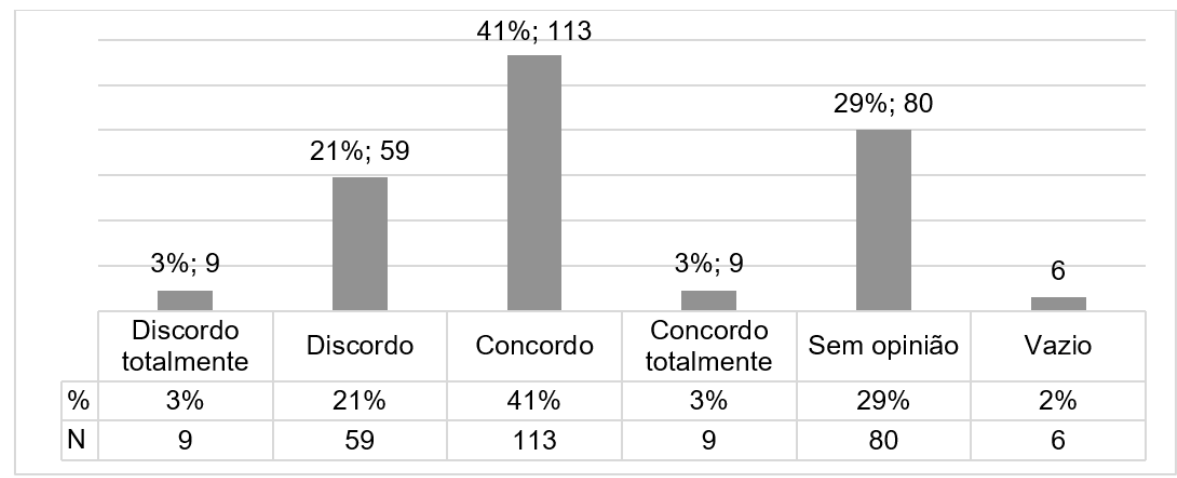

Fonte: os autores. 
Quando questionados sobre se a AEE promove a discussão sobre a organização interna da Escola (Gráfico 5), 62\% dos respondentes concordam com a afirmação, 9\% afirmam concordar totalmente, ao passo que 7\% discordam. Apenas $2 \%$ discordam totalmente e $19 \%$ referem não ter opinião.

Gráfico 5 - A AEE (Avaliação Externa das Escolas) promove a discussão sobre a organização interna da Escola

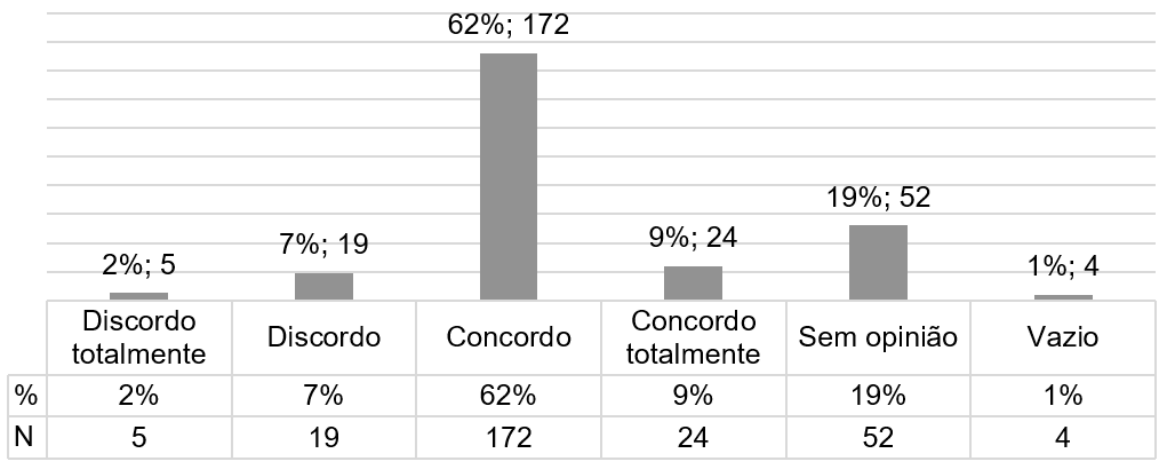

Fonte: os autores.

Relativamente à AEE privilegiar a orientação para os resultados de aprendizagem dos alunos (Gráfico 6), 54\% dos inquiridos concordam com a afirmação, tendo discordado 11\%. Dez por cento dos respondentes concordam totalmente e 3\% discordam totalmente. Dos inquiridos, $21 \%$ referem não ter opinião.

Gráfico 6 - A AEE (Avaliação Externa das Escolas) privilegia a orientação para os resultados de aprendizagem dos alunos

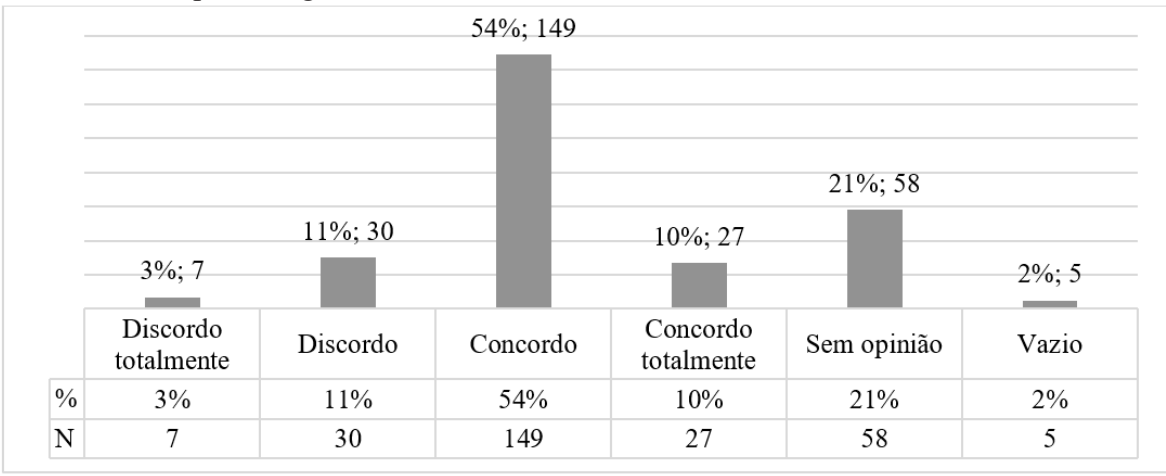

Fonte: os autores. 
Sobre a opinião dos respondentes sobre a melhoria dos apoios pedagógicos aos alunos devido à AEE da IGEC (Gráfico 7), 42\% revelam não ter opinião e 24\% referem concordar com a afirmação. Discordam da afirmação 22\%, 8\% discordam totalmente e $2 \%$ referem concordar totalmente.

Gráfico 7 - Os apoios pedagógicos aos alunos melhoraram em função da AEE (Avaliação Externa das Escolas) da IGEC

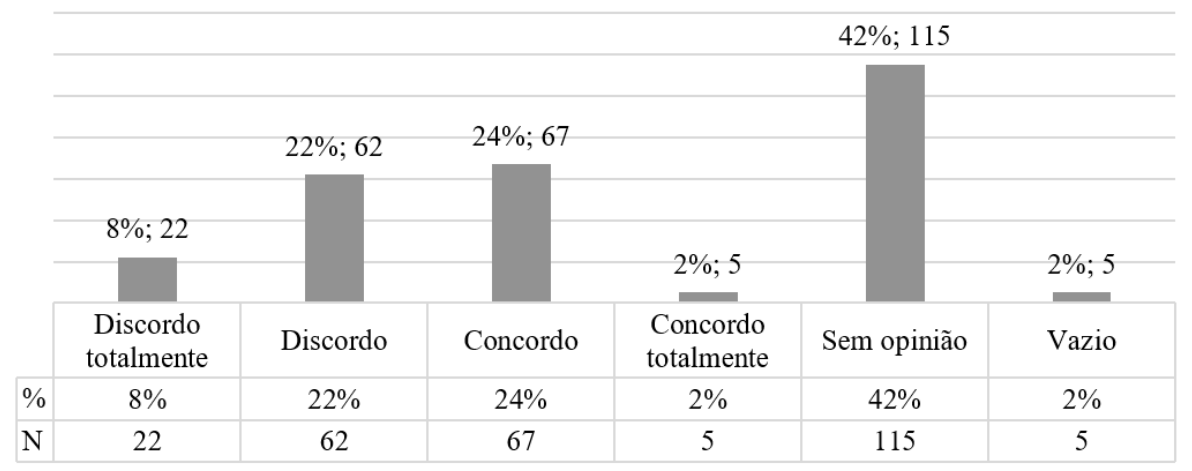

Fonte: os autores.

Relativamente à contribuição da AEE para a implementação da diferenciação pedagógica dos alunos (Gráfico 8), a maioria dos inquiridos (40\%) indica não ter opinião, $27 \%$ referem concordar e $24 \%$ discordam. Do total dos inquiridos, $4 \%$ discordam totalmente, e $2 \%$ concordam totalmente com a afirmação.

Gráfico 8 - A AEE (Avaliação Externa das Escolas) tem contribuído para a implementação da diferenciação pedagógica dos alunos

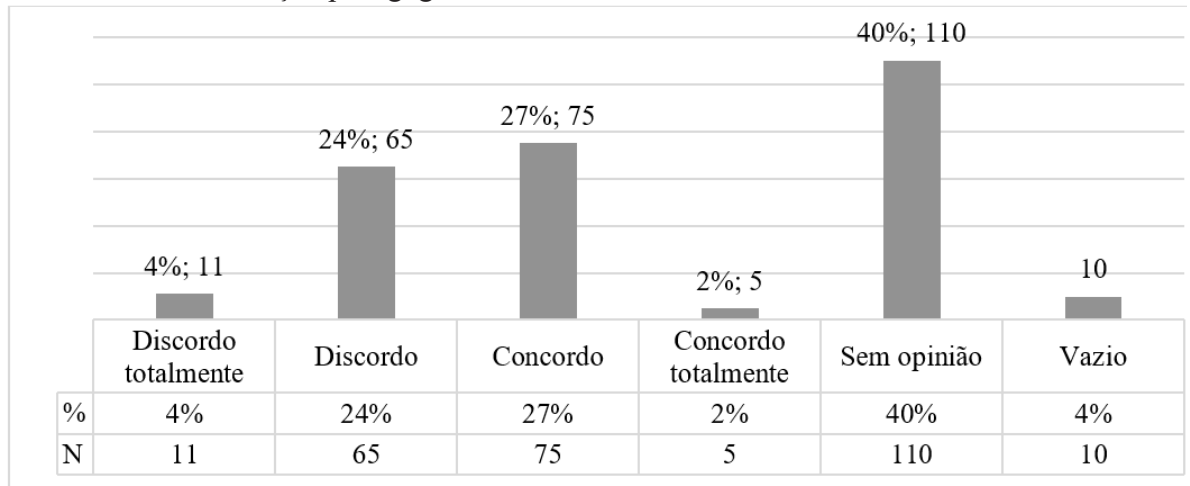

Fonte: os autores. 
Ao nível da utilização, por parte da direção e gestão da escola, dos resultados da AEE da IGEC para promover a imagem social da própria escola (Gráfico 9) a maioria dos respondentes refere concordar com a afirmação (49\%). A segunda situação mais prevalente remete para os inquiridos que manifestam não ter opinião, com $38 \%$. A concordância total dos respondentes mereceu $6 \%$ das respostas. A discordância é indicada por $5 \%$ dos inquiridos. Somente $2 \%$ mencionam discordar totalmente.

Gráfico 9 - A direção da escola utiliza os resultados da AEE (Avaliação Externa das Escolas) da IGEC para promover a imagem social da própria escola

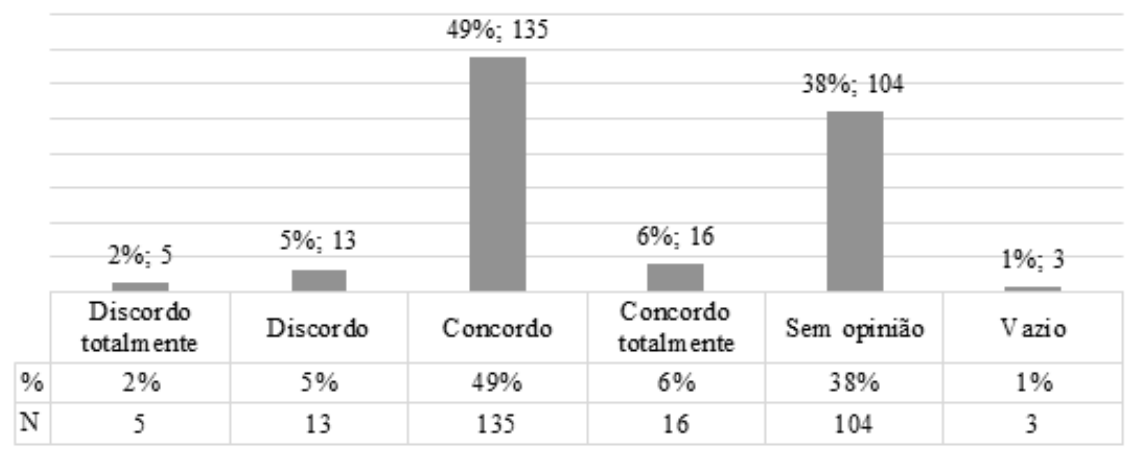

Fonte: os autores.

Por fim, na sua maioria (49\%) os respondentes referem concordar que a AEE valoriza a Avaliação Externa de Aprendizagens (provas no $9^{\circ}$ ano e exames nos $11^{\circ}$ e $12^{\circ}$ anos) (Gráfico 10 ). Sem opinião registam-se 33\% das respostas, $12 \%$ dos inquiridos referem concordar totalmente, e 3\% discordam. Apenas 1\% dos respondentes discordam totalmente.

Gráfico 10 - A AEE (Avaliação Externa das Escolas) da IGEC valoriza a Avaliação Externa de Aprendizagens (provas no $9^{\circ}$ ano e exames no $11^{\circ}$ e $12^{\circ}$ anos)

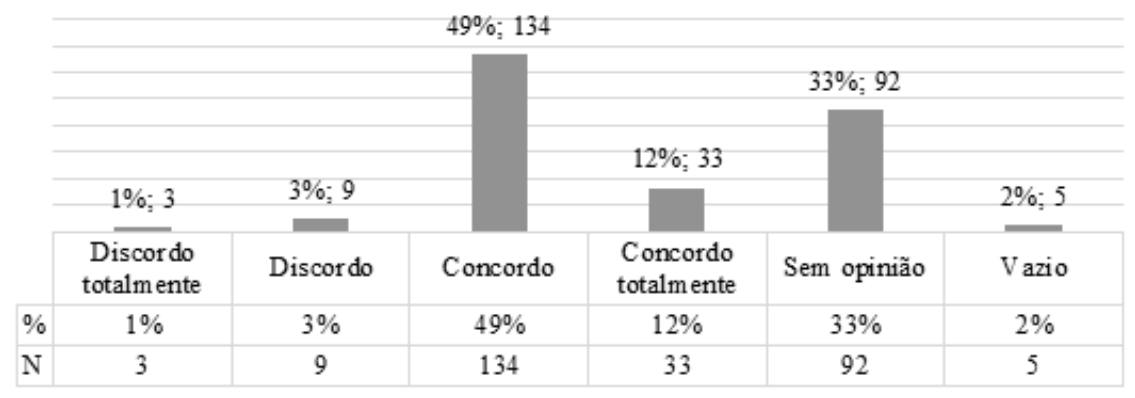

Fonte: os autores. 


\section{DISCUSSÃO DOS RESULTADOS}

Os resultados do estudo apontam para o facto de a AEE desempenhar um papel central na reestruturação das práticas curriculares dos docentes em Portugal.

Sabendo-se que o currículo está intrinsecamente relacionado com o contexto educativo e com base nos resultados do estudo, podemos afirmar que, em Portugal, existe a possibilidade de o conceito de currículo sofrer uma recontextualização promovida em grande medida pela AEE. As transformações curriculares são, sobretudo, percecionadas pelos docentes inquiridos através do enfoque na articulação curricular e na avaliação das aprendizagens dos alunos, bem como na escola enquanto organização educativa que promove o sucesso da aprendizagem dos alunos com base num serviço de qualidade, cujos resultados são submetidos a um julgamento social e dependendo, inclusive, do marketing que a própria escola realiza através da promoção da sua imagem, como podemos confirmar nos resultados deste estudo (Gráfico 9). Porém, se considerarmos as afirmações com discordância acima dos $20 \%$, uma parte significativa dos docentes inquiridos também demonstra que não concorda com o facto de a AEE contribuir para o desenvolvimento profissional docente (Gráfico 4), para a implementação da diferenciação pedagógica (Gráfico 8), ou que os apoios pedagógicos aos alunos melhoraram em função da AEE (Gráfico 7), o que nos leva a formular a seguinte questão: Que recontextualização curricular ocorre em Portugal com base na AEE, havendo uma perceção dos docentes de que a AEE não contribui para o desenvolvimento profissional docente, para a implementação da diferenciação pedagógica, nem para a melhoria dos apoios pedagógicos?

De acordo com o estudo, podemos afirmar que existe uma tensão entre a AEE e as práticas curriculares dos docentes em Portugal, à semelhança do que é afirmado por Marchesi (2002, p. 33) quando se refere à avaliação das escolas: "Poucos são os professores que duvidam da sua importância e da sua utilidade. E contudo, muitos desconfiam da forma como está sendo posta em prática.". Este ponto é central na reflexão que aqui trazemos. Acreditamos que os efeitos da AEE no currículo apresentados neste estudo demonstram, não apenas, as transformações vividas neste campo, mas também, as necessidades que são percecionadas pelos docentes. Considerando o que se defende em um dos objetivos da AEE - "contribuir para a regulação da educação, dotando os responsáveis pelas políticas educativas e pela administração das escolas de informação pertinente" (INSPEÇÃO-GERAL DA EDUCAÇÃO E CIÊNCIA, 2016c, 
p. 42) - e reconhecendo que a avaliação tem como objetivo determinar o valor do que é avaliado (SCRIVEN, 1967) ou de determinado objeto (SCRIVEN, 1996), reiteramos que é urgente ter em conta as condições das escolas e dos seus atores educativos para uma mudança educativa, uma vez que a implementação do sistema de AEE já está a produzir um efeito visível na recontextualização do currículo. A avaliação das escolas "é um fator imprescindível na orientação das mudanças nas escolas" (MARCHESI, 2002, p. 33-34), sendo, para isso, necessário promover a cumplicidade entre a AEE, as escolas e os seus atores, de modo a criar climas de confiança que permitam a reorientação da mudança educativa (FULLAN, 1991). A este nível, os resultados deste estudo demonstram que neste segundo ciclo de AEE ainda se está longe do que seria desejável, se considerarmos a percentagem significativa de docentes que revelam indefinição relativamente à melhoria dos apoios pedagógicos e à contribuição da $\mathrm{AEE}$ para a diferenciação curricular, quando a própria AEE tem como foco o planeamento, a articulação e as práticas de ensino nos seus campos de análise (INSPEÇÃO-GERAL DA EDUCAÇÃO E CIÊNCIA, 2016b).

A AEE, enquanto bússola orientadora das escolas, deverá constituirse como indissociável da confiança dos atores educativos e da restante sociedade, catalisando processos positivos de mudança educativa, isto é, dinâmicas socioeducativas e institucionais que atinjam os diferentes atores educativos numa lógica de desenvolvimento contínuo num "empreendimento coletivo que busque compreender os sentidos múltiplos e até mesmo os contraditórios processos relacionais." (DIAS SOBRINHO, 1995, p. 59). Sabemos que em educação toda a mudança é complexa, ambígua e até possivelmente ameaçadora (CORTESÃO, 1993), mas admitimos que um trajeto com base nestas representações poderá refletir-se numa maior consciencialização das potencialidades e necessidades que hoje se fazem sentir nas escolas e, consequentemente, em reflexões mais credíveis que poderão despoletar ações mais significativas. Um sistema de AEE que promova a avaliação com o intuito de orientar a decisão, quer das escolas (decisões internas) através de processos de autoavaliação, quer do governo (decisões externas), contribuirá para o aumento do seu impacto na educação e na diminuição da alienação, tendencialmente demonstrada pelos docentes sobre a AEE, à semelhança do que é apresentado no presente estudo, com base nos valores de indefinição na opinião relativas às afirmações que variam entre 19\% e 42\% (FITZPATRICK; SANDERS; WORTHEN, 2012). 
Neste estudo, a afirmação que mereceu maior concordância dos inquiridos está relacionada com a importância da AEE para a discussão sobre a organização interna da Escola, o que de certo modo contraria o que Afonso (2015, p. 221) tem vindo a alertar, quando defende: "há um claro desequilíbrio a favor do pilar da avaliação externa [sendo necessário] reforçar e revalorizar o pilar da autoavaliação, no sentido de redefinir interações, produzir melhores sinergias e maximizar as vantagens recíprocas", o que nos leva a acreditar que estes valores se devem, sobretudo, ao facto de serem escolas acompanhadas pelo Observatório. Verifica-se, assim, que o desequilíbrio entre a AEE e a autoavaliação, para o qual Afonso (2015) nos alerta, pode ser diminuído com a implementação de mecanismos como, por exemplo, a criação de parcerias entre as escolas e as universidades, como é o caso do Observatório. Para que a AEE seja promotora da autoavaliação não basta convocar a autoavaliação como campo de análise da AEE, é necessário desenvolver mecanismos que auxiliem os atores educativos na estruturação da sua aplicação, de modo a alcançar a inovação no interior da escola (THURLER, 2001).

A avaliação educacional pode ser útil para o desenvolvimento da educação, nomeadamente se estiver articulada com as características do campo educacional, a nível da sua consistência externa, e com a satisfação de todos os atores envolvidos (comunidade educativa e envolvente), a nível da sua consistência interna, capacitando-a para se tornar em:

um patrimônio público a ser apropriado e exercido como ins-
trumento de consolidação da educação como bem público; uma
prática participativa e um empreendimento ético a serviço do
fortalecimento da responsabilidade social da educação, enten-
dida principalmente como o cumprimento científica e social-
mente relevante dos processos de produção de conhecimentos
e de formação de sujeitos com autonomia epistêmica, moral,
social e política. (DIAS SOBRINHO, 2008, p. 194).

Sobre a avaliação externa, Scriven (1967) defende que é, sobretudo, aquela em que o papel primordial na balança da avaliação é sumativo onde o outro papel é reconhecido à avaliação interna ou autoavaliação (formativa). Na esteira das ideias de Freeman e Sturdy (2015) relativas ao conhecimento nas políticas, consideramos que a AEE, pelo seu cariz sumativo, gera para as escolas um conhecimento codificado que desencadeia, da parte destas, a tendência para valorização de um currículo codificado, isto é, suportado em símbolos quantificáveis e tangíveis que permitam retroalimentar o 
ciclo sumativo. Tomemos como exemplo a Avaliação Externa de Aprendizagens (provas no $9^{\circ}$ ano e exames no $11^{\circ}$ e $12^{\circ}$ anos) que produz um rácio normalizado, permitindo a comparação entre contextos complexos e de outra forma incomparáveis, sendo essa racionalização semelhante à aplicada na AEE, consumada através dos rankings das escolas. Na perceção dos docentes inquiridos, a relação entre ambas é tão próxima que concordam com o facto de que a AEE valoriza a Avaliação Externa de Aprendizagens (Gráfico 10), enfatizando a abordagem sumativa e quantitativa da avaliação e, consequentemente, do conhecimento. No que lhe diz respeito, a autoavaliação das escolas potencia a criação de conhecimento integrado, com base no seu cariz formativo (SCRIVEN, 1967), que poderá desencadear a tendência para estimar um currículo integrado, consubstanciado na flexibilização curricular, que pela sua irracionalidade abraça a complexidade e a idiossincrasia de cada contexto socioeducativo.

\section{EM SÍNTESE}

Os resultados do estudo empírico apresentado remetem para uma maior problematização da AEE, sobretudo ao nível dos seus efeitos nas perceções dos docentes, agentes fundamentais na escola e na sua valorização organizacional, curricular e pedagógica. Este estudo, ainda que não possa ser considerado estatisticamente significativo, sendo necessário ampliar a amostragem e diversificar os níveis de docência, já que os docentes inquiridos foram educadores de infância e professores dos ensinos básico e secundário, serve de estudo exploratório para aprofundar uma realidade que tem sido introduzida pela avaliação externa, quase sempre de cariz sumativo, e com incidência na mudança desejada administrativamente. Na linha de pensamento de Dias Sobrinho, sublinhamos que é necessário "priorizar a avaliação formativa" (1995, p. 66) no campo da avaliação das escolas, potenciando a sua reconfiguração com sentido, ou seja, numa perspetiva de valorização do currículo integrado.

\section{REFERÊNCIAS}

AFONSO, A. Do desequilíbrio do pilar da autoavaliação no modelo de avaliação externa: apontamentos. In: CONSELHO NACIONAL DE EDUCAÇÃO (Org.). Avaliação Externa das Escolas. Lisboa: Conselho Nacional de Educação, 2015. p. 217-225. Disponível em: $<\mathrm{http} / / / \mathrm{www} . c n e d u . p t / c o n t e n t / e d i c o e s /$ seminarios_e_coloquios/LIVROCNE_AVALIA $\%$ C3\% $\% 7 \%$ C3\%83O_EXTERNA_DAS_ESCOLACAS. pdf>. Acesso em: 12 fev. 2017. 
CONSELHO NACIONAL DE EDUCAÇÃO. Conselho Nacional de Educação. [2015]. Disponível em: <http://www.cnedu.pt/pt/apresentacao/missao >. Acesso em: 11 jan. 2017.

CONSELHO NACIONAL DE EDUCAÇÃO. Parecer n. ${ }^{\circ} \mathbf{3} / \mathbf{2 0 1 0}, 9$ de junho de 2010. Parecer sobre avaliação externa das escolas (2007-2009). Disponível em: < http://www.cnedu.pt/content/antigo/images/stories/Publicao_Parecer_AEE.pdf $>$. Acesso em: 11 jan. 2017.

CORTESÃO, L. A avaliação formativa - que desafios? Porto: Edições Asa, 1993.

DIAS SOBRINHO, J. Avaliação Educativa: produção de sentidos com valor de formação. Avaliação, Campinas, SP, v. 13, n. 1, p. 193-207, mar. 2008. Disponível em: $<$ http://www.scielo.br/pdf/aval/v13n1/a11v13n1.pdf>. Acesso em: 18 fev. 2017.

DIAS SOBRINHO, J. Avaliação institucional, instrumento da qualidade educativa. A experiência da Unicamp. In: SOBRINHO, J. D.; BALZAN, N. C. (Org.). Avaliação institucional: Teoria e experiências. São Paulo: Cortez Editora, 1995. p. 53-86.

EUROPEAN COMISSION/EACEA/EURYDICE. Garantia da Qualidade na Educação: Políticas e Abordagens à Avaliação das Escolas na Europa. Relatório Eurydice. Luxemburgo: Serviço de Publicações da União Europeia, 2015a. Disponível em: <http://eacea.ec.europa.eu/education/eurydice>. Acesso em: 09 jan. 2017.

EUROPEAN COMMISSION/EACEA/EURYDICE. The Teaching Profession in Europe: Practices, Perceptions, and Policies. Eurydice Report. Luxembourg: Publications Office of the European Union, 2015b. Disponível em: <http://eacea. ec.europa.eu/education/eurydice/documents/thematic_reports/184EN.pdf $>$. Acesso em: 16 fev. 2017.

FIALHO, I. A qualidade de ensino e a avaliação das escolas em Portugal. Contributos para a sua história recente. Educação: Temas e problemas, Évora, n. 7, v. 4, p. 99-116, 2009.

FITZPATRICK, J. L.; SANDERS J. R.; WORTHEN, B. R. Program Evaluation. Alternative approaches and practical guidelines. 4. ed. New Jersey: Pearson Education, Inc., 2012.

FREEMAN, R.; STURDY, S. Knowledge in Policy: Embodied, Inscribed, Enacted. Bristol: Policy Press, 2015.

FULLAN, M. The meaning of educational change. In: FULLAN, M. The new meaning of educational change. New York: Teachers College Press, 1991. p. 30-46. 
INSPEÇÃO-GERAL DA EDUCAÇÃO. Quadro de Referência para a Avaliação de Escolas e Agrupamentos de Escolar. Avaliação Externa das Escolas 2010-2011. 2010. Disponível em: <http://www.ige.min-edu.pt/upload/AEE_2011/ AEE_10_11_Quadro_Referencia.pdf>. Acesso em: 16 jan. 2017.

INSPEÇÃO-GERAL DA EDUCAÇÃO. Avaliação Externa das Escolas: Avaliar para a melhoria e a confiança - 2006-2011. Lisboa: Ministério da Educação, 2011a. Disponível em: <http://www.ige.min-edu.pt/upload/Relatorios/AEE_2006_2011_ RELATORIO.pdf>. Acesso em: 05 jan. 2017.

INSPEÇÃO-GERAL DA EDUCAÇÃO. Propostas para um novo ciclo de avaliação externa de escolas. Relatório Final do Grupo de Trabalho. Lisboa: Ministério da Educação, 2011b. Disponível em: <http://www.ige.min-edu.pt/upload/Relatorios/ AEE2_GT_2011_RELATORIO_FINAL.pdf>. Acesso em: 5 jan. 2017.

INSPEÇÃO-GERAL DA EDUCAÇÃO E CIÊNCIA. Avaliação Externa das Escolas. [2011b]. Disponível em: $<$ http://www.ige.min-edu.pt/content_01.asp?BtreeID=0 3/01\&treeID=03/01/03/00\&auxID=>. Acesso em: 16 jan. 2017.

INSPEÇÃO-GERAL DA EDUCAÇÃO E CIÊNCIA. Escala de avaliação. Avaliação Externa das Escolas 2016-2017. Lisboa: Inspeção-Geral da Educação e Ciência. 2016a. Disponível em: <http://www.ige.min-edu.pt/upload/AEE_20162017/AEE_16_17_(3)_Escala_de_Avaliacao.pdf $>$. Acesso em: 16 jan. 2017.

INSPEÇÃO-GERAL DA EDUCAÇÃO E CIÊNCIA. Quadro de Referência para a Avaliação Externa das Escolas. Avaliação Externa das Escolas 2016-2017. Lisboa: Inspeção-Geral da Educação e Ciência, 2016b. Disponível em: <http:// www.ige.min-edu.pt/upload/AEE_2016-2017/AEE_16_17_(1)_Quadro_de_Referencia.pdf $>$. Acesso em: 16 jan. 2017.

INSPEÇÃO-GERAL DA EDUCAÇÃO E CIÊNCIA. Metodologia do Sistema de AEE. Lisboa: Inspeção-Geral da Educação e Ciência, 2016c. Disponível em: $<$ http://www.ige.min-edu.pt/upload/AEE_2016-2017/AEE_16_17_(4)_Metodologia. pdf $>$. Acesso em: 16 jan. 2017.

MARCHESI, A. Mudança educativa e avaliação das escolas. In: AZEVEDO, J. (Org.). Avaliação das escolas: consensos e divergências. Porto: Edições Asa, 2002. p. 33-49.

MINISTÉRIO DA EDUCAÇÃO. Educação e Formação em Portugal. Lisboa: Ministério da Educação, 2007. Disponível em: <http://www.dgeec.mec.pt/np4/97/\% 7B \$clientServletPath\%7D/?newsId=147\&fileName=educacao_formacao_portugal. pdf $>$. Acesso em: 18 jan. 2017. 
OLIVEIRA, P. et al. Relatório final da actividade do Grupo de Trabalho para Avaliação das Escolas. Lisboa: Ministério da Educação, 2006. Disponível em: $<$ http://www.ige.min-edu.pt/upload/Relatorios/AEE_06_RELATORIO_GT.pdf $>$. Acesso em: 25 jul.2017.

PACHECO, J. A. Resultados globais do Projeto. In: BARREIRA, C.; BIDARRA, M.; VAZ-REBELO, M. (Orgs.). Estudos sobre Avaliação Externa de Escolas. Porto: Porto Editora, 2016, p. 263-271.

\section{PACHECO, J. A. Relatório Final do Projeto de Investigação "Impacto e} Efeitos da Avaliação Externa de Escolas do Ensino não Superior”. Braga: Universidade do Minho, 2015. Disponível em: <http://webs.ie.uminho.pt/avaliacaoexternaescolas/Relat\%C3\%B3rio\%20\%20AEENS.\%202015..pdf >. Acesso em: 6 ago. 2017.

PORTUGAL. Decreto Regulamentar n. ${ }^{\mathbf{1}}$ 15/2012, de 27 de janeiro de 2012. Define a Inspeção-Geral da Educação e Ciência como um serviço central da administração direta do Estado dotado de autonomia administrativa. Disponível em: $<$ http:// www.ige.min-edu.pt/upload/Legisla\%C3\%A7\%C3\%A3o/Decreto_Regulamentar_15_2012.pdf>. Acesso em: 13 abr. 2017.

PORTUGAL. Lei n. ${ }^{\circ}$ 31/2002, de 20 de dezembro de 2002. Aprova o sistema de educação e do ensino não superior, desenvolvendo o regime previsto na Lei n. ${ }^{\circ}$ 46/86, de 14 de outubro (Lei de Bases do Sistema Educativo). Disponível em: $<$ http://www.ige.min-edu.pt/upload/Legisla\%E7\%E3o/Lei_21_2002.pdf $>$. Acesso em: 01 fev. 2017.

SCRIVEN, M. The methodology of evaluation. In: TAYLOR R. W.; GANGE, R. M.; SCRIVEN, M. (Ed.). Perspectives of curriculum evaluation. Chicago: Rand McNally, 1967. p. 39-83.

SCRIVEN, M. Types of evaluation and types of evaluator. Evaluation Practice, $n$. 17, p. 151-162, 1996. Disponível em: <http://journals.sagepub.com/doi/pdf/10.1177/ $109821409601700207>$. Acesso em: 19 jun. 2017.

THURLER, M. Inovar no Interior da Escola. Porto Alegre: Artmed, 2001.

Recebido em: 26 de setembro de 2017

Aceito em: 23 de novembro de 2017

Endereço para correspondência: Campus de Gualtar, 4710-057, Braga, Portugal; joanarfsousa@gmail.com 